\title{
Cardiovascular comorbidity and death from COVID-19: Prevalence and differential characteristics
}

\author{
Julia Playán-Escribano, Zaira Gómez-Álvarez, Teresa Romero-Delgado, \\ Carlos Nicolás Pérez-García, Daniel Enríquez-Vázquez, Isidre Vilacosta \\ Instituto Cardiovascular, Hospital Clínico San Carlos, Madrid, Spain
}

Coronavirus disease (COVID-19), caused by SARS-CoV-2, originated as a global pandemic and has had a major impact on Europe. Spain, with more than 1,600,000 confirmed cases and a fatality rate of approximately $2.75 \%$, is one of the most affected countries to date [1]. A high prevalence of cardiovascular (CV) comorbidity, consisting mostly of coronary artery disease (CAD) and arrhythmias, has been reported among the deceased $[2,3]$.

Additionally, a wide variety of CV manifestations has been described in COVID-19 patients, either as a result of the invasion of endothelial cells and myocardiocytes (carriers of the ACE receptor on their membrane) by the SARS-CoV-2, as a consequence of the cytokine storm [2] or due to impaired microcirculatory function [4].

The purpose herein, is to describe the prevalence of CV comorbidity in the patients who died on the hospital wards of a Spanish tertiary hospital and to examine the differences in baseline characteristics, laboratory findings, days until death and treatment received compared to those who died without these comorbidities.

All patients infected with SARS-CoV-2 who died in the hospital wards between March 9 and April 16, 2020, were consecutively included. Those who died in the intensive care unit were excluded on the grounds that their evolution and potential causes of morbidity and death might be different. Clinical and analytical variables were collected. Myocardial injury, measured as maximum elevation of troponin I, was analyzed. A patient who suffered an acute coronary syndrome with ST-segment elevation due to late thrombosis from a previously implanted stent was excluded from the analysis for this variable. The CURB-65 scale was used to stratify the risk at admission [5].

A total of 324 deceased patients were included, with an age of $81 \pm 10$ years, $44 \%$ of them were women, and a high prevalence of hypertension $(78 \%)$, dyslipidemia (58\%) and diabetes (34\%). Sixty-two $(19 \%)$ had a history of atrial fibrillation $(\mathrm{AF})$ and $40(12 \%)$ of previous CAD.

Patients with $\mathrm{AF}$ vs. patients without $\mathrm{AF}$ were older ( $85 \pm 6$ vs. $81 \pm 10$ years, $p=0.0006)$. They presented with a higher prevalence of hypertension $(90 \%$ vs. $75 \%, \mathrm{p}=0.012)$ and chronic kidney disease (53\% vs. $37 \%, \mathrm{p}=0.022)$ (Table 1 ).

Patients with CAD vs. patients without CAD, in turn, exhibited a higher prevalence of hypertension ( $95 \%$ vs. $76 \%, \mathrm{p}=0.006)$, dyslipidemia $(83 \%$ vs. $54 \%, \mathrm{p}=0.001)$ and ventricular systolic dysfunction ( $55 \%$ vs. $23 \%$, p < 0.001$)$. No differences were found in the presence of other comorbidities.

Most patients (88\%) had a CURB-65 score of 2 or higher on admission, with no differences noted between those with and without CV comorbidity.

Fifty-two percent of the patients who presented with maximum troponin values above the limit of normality $(0.05 \mathrm{ng} / \mathrm{mL})$ and $22 \%$ presented values higher than 5 times that limit. No differences were found in the presence of troponin elevation or in its quantitative value in patients with $\mathrm{AF}$ or CAD.

D-dimer elevation was present in $77 \%$ of patients, being less frequent in those with $\mathrm{AF}$ ( $80 \%$ vs. $63 \%, p=0.016$ ), irrespective of the anticoagulation received. No differences were found regarding the presence of lymphopenia, lactate dehydrogenase or ferritin elevation.

Address for correspondence: Julia Playán-Escribano, MD, Hospital Clínico San Carlos, Cardiology Department, Calle del Prof Martín Lagos, s/n, 28040 Madrid, Spain, tel: 0034646816859, e-mail: julia.playan@gmail.com

This article is available in open access under Creative Common Attribution-Non-Commercial-No Derivatives 4.0 International (CC BY-NC-ND 4.0) license, allowing to download articles and share them with others as long as they credit the authors and the publisher, but without permission to change them in any way or use them commercially. 


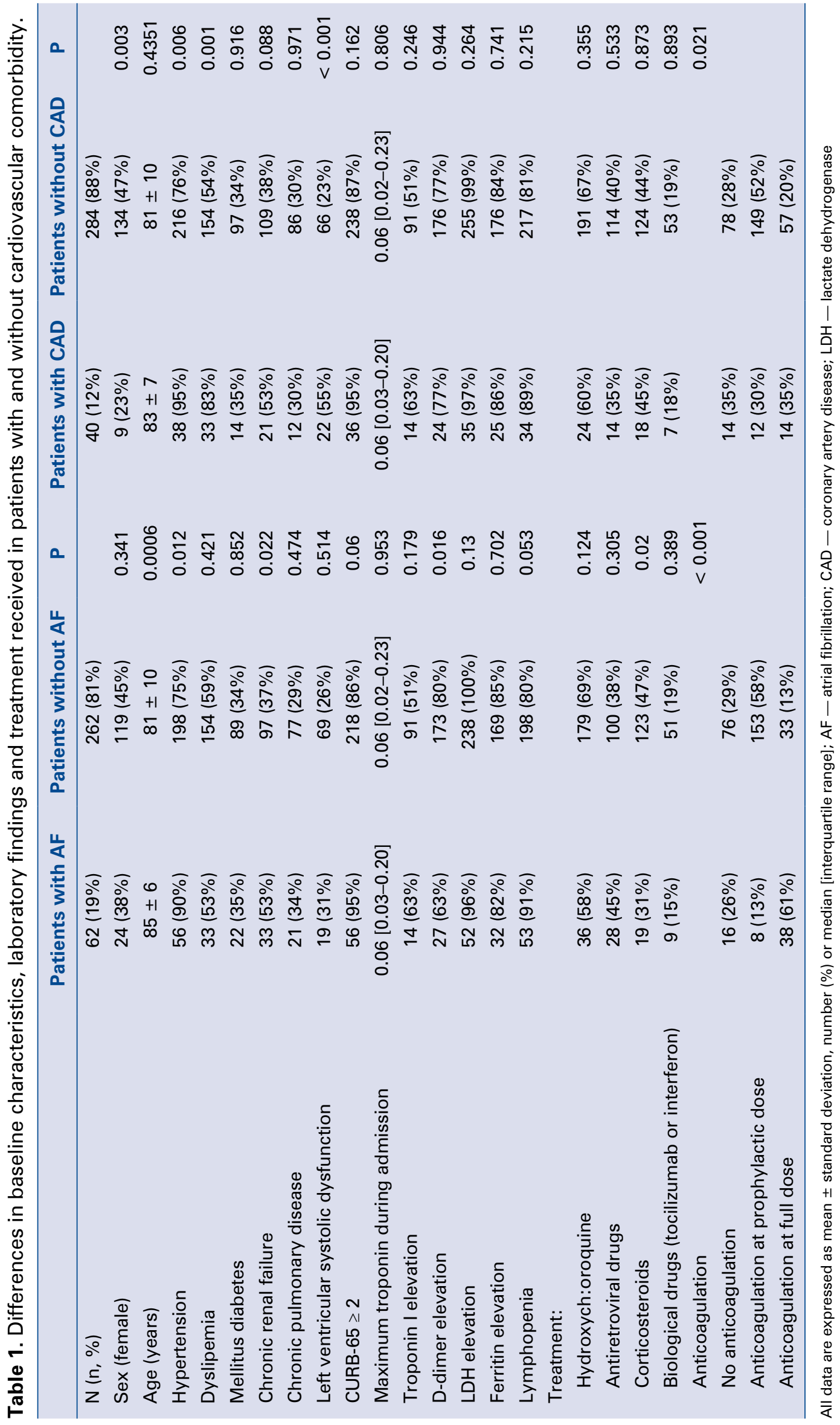


Regarding treatment, patients with AF more frequently received anticoagulation at full doses compared to patients without $\mathrm{AF}(61 \%$ vs. $13 \%$, $\mathrm{p}<0.001)$. However, the proportion of patients within this group without full-dose anticoagulation (39\%) is noteworthy. These numbers were thought to be either a result of potential drug interactions of oral anticoagulants or the critical clinical status or may be a combination of both. Furthermore, patients with $\mathrm{AF}$ received corticosteroids less frequently ( $31 \%$ vs. $47 \%, \mathrm{p}=0.02$ ). There were no significant differences in the use of antiretroviral drugs or hydroxychloroquine in any of the groups.

No differences were noted regarding the number of days from admission to death, nor in the analysis of cumulative survival (Log rank $p=0.5$ for cumulative survival of patients with AF vs. patients without AF; and Log rank $\mathrm{p}=0.358$ for cumulative survival of patients with CAD vs. patients without $\mathrm{CAD}$ ).

The prevalence of $\mathrm{AF}$ and $\mathrm{CAD}$ amongst those who died in the hospital wards in our center was lower than that reported in Italy by the Istituto Superiore di Sanità $(30 \% \mathrm{CAD}$ and $24.5 \% \mathrm{AF}$ among the deceased) [6], despite the fact that the presented population is slightly older $(81 \pm 10 \mathrm{vs}$. $79.5 \pm 8.1$ years $)$.

Although $\mathrm{CAD}$ or AF patients had more comorbidities and AF patients received less corticosteroids, their risk stratification on admission and the time from symptoms onset to death were similar.

The percentage of patients in the present study sample showed troponin elevation reached $52 \%$, much higher than the usual $8-12 \%$ amongst patients diagnosed with COVID-19 [7]. This higher frequency of troponin I elevation in the sample of deceased patients (compared to the general COVID-19 population with different outcomes), together with the absence of differences between the groups with and without $\mathrm{CV}$ comorbidity, seems to indicate that the development of myocardial insult depends fundamentally on the severity of the disease and not on the baseline characteristics of the patient, as it has been suggested in another series [8].

Due to the work overload caused by the pandemic, echocardiograms were not performed during the admission of most of the patients with myocardial injury defined as elevation of biomarkers. However, it would be interesting to know if this troponin elevation corresponded to impaired ventricular function, as had been described to be the case in sepsis [9].

Given the high prevalence of $\mathrm{CV}$ comorbidity in patients who develop severe forms of COVID-19, further research is needed on the management and prognosis of this population. Likewise, given the high incidence of myocardial insult amongst those with severe forms of the disease, the pathophysiological substrate of myocardial damage and the potential benefit of cardioprotective strategies should be studied.

\section{Conflict of interest: None declared}

\section{References}

1. Ministerio de Sanidad, Consumo y Bienestar Social. Actualización no 258. Enfermedad por el coronavirus (COVID-19). 2020. https://www.mscbs.gob.es/en/profesionales/saludPublica/ccayes/alertasActual/nCov-China/documentos/Actualizacion_135_COVID-19.pdf (Accessed November 26th 2020).

2. European Society of Cardiology. ESC guidance for the diagnosis and management of $\mathrm{CV}$ disease during the COVID-19 pandemic. 2020. https://www.escardio.org/Education/COVID-19-and-Cardiology/ESC-COVID-19-Guidance (Accessed November 26th 2020).

3. Kowalik MM, Trzonkowski P, Łasińska-Kowara M, et al. COVID-19 - Toward a comprehensive understanding of the disease. Cardiol J. 2020; 27(2): 99-114, doi: 10.5603/CJ.a2020.0065, indexed in Pubmed: 32378729.

4. Gąsecka A, Filipiak KJ, Jaguszewski MJ. Impaired microcirculation function in COVID-19 and implications for potential therapies. Cardiol J. 2020; 27(5): 485-488, doi: 10.5603/CJ.2020.0154, indexed in Pubmed: 33165898.

5. Lim WS, Baudouin SV, George RC, et al. BTS guidelines for the management of community acquired pneumonia in adults: update 2009. Thorax. 2009; 64 Suppl 3: iii1-ii55, doi: 10.1136/ thx.2009.121434, indexed in Pubmed: 19783532.

6. Onder G, Rezza G, Brusaferro S. Case-Fatality rate and characteristics of patients dying in relation to COVID-19 in Italy. JAMA. 2020; 323(18): 1775-1776, doi: 10.1001/jama.2020.4683, indexed in Pubmed: 32203977.

7. Lippi G, Plebani M. Laboratory abnormalities in patients with COVID-2019 infection. Clin Chem Lab Med. 2020; 58(7): 1131-1134, doi: 10.1515/cclm-2020-0198, indexed in Pubmed: 32119647.

8. Lorente-Ros A, Monteagudo Ruiz JM, Rincón LM, et al. Myocardial injury determination improves risk stratification and predicts mortality in COVID-19 patients. Cardiol J. 2020; 27(5): 489-496, doi: 10.5603/CJ.a2020.0089, indexed in Pubmed: 32589258.

9. Kim JS, Kim M, Kim YJ, et al. Troponin testing for assessing sepsis-induced myocardial dysfunction in patients with septic shock. J Clin Med. 2019; 8(2), doi: 10.3390/jcm8020239, indexed in Pubmed: 30759844. 